\title{
Original $\mid$ GEFITINIB IN PRETREATED ADVANCED NON-SMALL CELL LUNG CANCER Article (NSCLC): ANALYSIS OF EFFICACY
}

\section{Mahmoud Abdelsalam}

King Faisal Specialist Hospital and Research Center, Cancer Center, Medical Oncology Unit.

Kasr El-Aini Center for Clinical Oncology, Faculty of Medicine Cairo University.

\begin{abstract}
Introduction: To evaluate the efficacy and tolerability of gefitinib (Iressa (ZD 1839); Astrazeneca, Willington, DE), a novel epidermal growth factor receptor tyrosine kinase inhibitor, in patients with pretreated advanced non-small cell lung cancer (NSCLC).

Materials and Methods: Patients with pretreated advanced NSCLC received gefitinib at a daily dose of 250 mg orally until disease progression. Patients included in this study all had measurable, locally advanced or metastatic NSCLC, pretreated with at least one line of platinum based chemotherapy.

Results: From June 2004 to February 2006, 18 consecutive patients were enrolled onto the study, the overall disease control rate was 66.7\% (partial response (PR), 11.1\%; stable disease (SD) 55.6\%), median TTP was 2.9 months (95\% confidence interval 2.3 to 3.2 months) and median PFS was 3 months (95\% confidence interval 2.4 to 3.6 months), median OS from start of gefitinib was 8.4 months (95\% confidence interval 5 to 11.8 months). Univariete analysis of prognostic factors revealed that, response to gefitinib and longer duration of gefitinib treatment showed a better PFS, while only longer duration of gefitinib treatment showed a better OS.

Conclusion: Gefitinib showed clinically meaningful anti-tumor activity and provided symptom relief as second and third line treatment in pre-treated advanced NSCLC. Gefitinib is tolerable and had favorable adverse events.
\end{abstract}

Key Words: Gefitinib in pretreated, advanced, non-small, cell Lung, cancer (NSCLC).

Corresponding Author: Email: mahmoudabdelsalam@hotmail.com, mabdelsalam@kfshrc.edu.sa

\section{INTRODUCTION}

Lung cancer is the most common cause of cancer deaths in both men and women worldwide ${ }^{1}$. Despite advances in treatment, such as combination chemotherapy and chemo-radiation, survival has improved very little over the past few decades². A meta-analysis demonstrated that the median survival time for patients with advanced disease receiving cisplatin-based chemotherapy is around 6 months $^{3}$. The five-year survival rate for all stages is less than $15 \%{ }^{4}$. Prognosis is particularly poor for patients who have progressive disease following chemotherapy; for Non-Small Cell Lung Cancer (NSCLC) patients receiving best supportive care (BSC) after 1 or more prior chemotherapy regimen, median survival time is just 16 weeks, with 1 - year survival rate of $16 \%^{3-5}$. It has become generally accepted that systemic chemotherapy is beneficial in terms of improved survival and quality of life (QOL) in those with advanced NSCLC ${ }^{3-6}$. As more patients receive $1^{\text {st }}$ line chemotherapy, the need for effective second-line therapy is increasing. Currently, docetaxel and pemetrexed, having demonstrated survival benefits over BSC for patients who have been failed after previous platinum-based chemotherapy ${ }^{7,8}$.

Gefitinib (ZD 1839, Iressa, Astra Zeneca, London, United Kingdom)is an orally active, selective EGFRTKI that demonstrated antitumor activity against a variety of human cancer cell lines expressing EGFR, including ovarian, breast and colon and it is active in a range of xenograft models, including colon, prostate and NSCLC ${ }^{9-11}$. Phase I studies evaluating the safety and tolerability of gefitinib identified rash and diarrhea as unique and dose related toxicities. Notably, an $11 \%$ response rate (RR) has been observed among the 100 NSCLC patients enrolled onto these trials ${ }^{11}$. In phase II trial gefitinib showed a RR of $16 \%$ with overall disease control rate was $58.7 \%{ }^{12}$. In phase III trial In the Iressa Survival Evaluation in Lung Cancer (ISEL), gefitinib failed to show survival benefit over BSC, but in, planned subset analyses in never smokers and those of Asian ethnicity, gefitinib showed significantly longer survival compared to placebo ${ }^{13,14}$.

In current trial we planned to investigate the use of gefitinib in patients with pretreated advanced or metastatic NSCLC.

\section{MATERIALS AND METHODS}

The 18 patients included in our study were pathologically proven NSCLC in King Faisal Specialist Hospital and Research Center (KFSHRC) during the period 2004-2007. 
All patients included in this study had measurable, locally advanced or metastatic NSCLC, pretreated with at least one line of platinum based chemotherapy. Patients with locally advanced disease were considered eligible if they were pretreated with front line platinumbased chemotherapy and \pm radiation. Patients were older than 18 years of age and had an Eastern cooperative group (ECOG) performance status of 2 or less, a life expectancy of at least 12 weeks, EGFR expression by immunohistochemistry, a normal complete blood picture with accepted hemoglobin of 9gram/liter or more, bilirubin less than 1.5 -fold of the upper limit of normal (ULN), ALT or AST less than 3-fold of the ULN and normal renal profile. Patients were ineligible if they had evidence of prior/concurrent malignancy. The study was conducted after the approval from our institutional review board.

In this study, consecutive patients with pretreated NSCLC received gefitinib at a daily dose of $250 \mathrm{mg}$ administered until disease progression. Gefitinib was taken once daily in the morning, at approximately the same time each day. Baseline evaluation included a complete history and physical examination, complete blood cell count and serum chemistry analysis, urinalysis, chest $\mathrm{x}$ ray and total-body computed tomography scan. Other imaging modalities, such as magnetic resonance imaging and bone scintigraphy, were performed according to specific clinical indications. All baseline imaging procedures were performed within 4 weeks before study entry. Biochemical screening was performed every 4 weeks, assessing renal hepatic and electrolyte profiles. Toxic effects were assessed every 28 days according to the National Cancer Institute common toxicity criteria version 2. Patients were evaluated for response according to the Response Evaluation Criteria in Solid Tumors $(\text { RECIST })^{15}$. Tumor response was assessed by computed tomography scan every 2 months, with a confirmatory evaluation to be repeated in responding patients at least 4 weeks after the initial determination of response.

\section{Statistical Analysis:}

All statistics were Performed with SPSS soft ware (Statistical Package for Social Science, Version 14). Description statistics was presented as number and percentage (frequency distribution). Fisher's exact test was used to compare the results for significance with p value of $<0.05$ was considered as significant results. Over all survival (OS) was defined as time from date of start of gefitinib to date of last follow up or death. Progression free survival (PFS) was defined as time from date of start of gefitinib treatment to date of progression or death. Time to progression (TTP) is defined as time from date of achieving CR or PR to date of recurrence. Cox regression analysis was used for univariate and multivariate analysis of factors affecting survival, with a p-value of $<0.05$ was used for significance. The KaplanMeire method was used to determine survival curves and the log-rank test was used to compare survival in different populations, log-rank $\mathrm{P}$ value was used with a significance of $<0.05$.

\section{RESULTS}

From June 2004 to February 2007, 18 patients with previously treated NSCLC patients were treated with gefitinib in KFSHRC. Characteristics of the patients are listed in (Table 1). The majority of the patients were male (72.2\%), with a mean age of 51.2 years (range, 36 to 68 years) and with ECOG performance status (0 to 1 in $72.2 \%$ ). Histology was adenocarcinoma in $77.8 \%$ of patients (one was broncho-alveolar) and squamous cell carcinoma in $22.2 \%$. All patients included in the trial had received platinum-based chemotherapy and 33.3\% of them had received two lines of chemotherapy including platinum, taxanes and gemcitabine. All stage IIIB patients were pretreated with mediastinal radiotherapy as part of a chemo radiation integrated approach.

Table 1: Patients Characteristics (18 Patients).

\begin{tabular}{|c|c|c|c|}
\hline Factor & & No & $\%$ \\
\hline \multicolumn{4}{|l|}{ Age } \\
\hline & Mean & \multicolumn{2}{|l|}{$51.22+/-8.822$} \\
\hline & Range & \multicolumn{2}{|l|}{$38-68$} \\
\hline \multicolumn{4}{|l|}{ Sex } \\
\hline & Male & 13 & 72.2 \\
\hline & Female & 5 & 27.8 \\
\hline \multicolumn{4}{|c|}{ Smoking } \\
\hline & Yes & 13 & 72.2 \\
\hline & No & 3 & 16.7 \\
\hline & Unknown & 2 & 11.1 \\
\hline \multicolumn{4}{|c|}{ Histology } \\
\hline & Adenocarcinoma & 14 & 77.8 \\
\hline & Squamous & 4 & 22.2 \\
\hline \multicolumn{4}{|l|}{ Stage } \\
\hline & IIIB & 7 & 38.9 \\
\hline & IV & 11 & 61.1 \\
\hline \multicolumn{4}{|c|}{ ECOG PS } \\
\hline & 1 & 13 & 72.2 \\
\hline & 2 & 5 & 27.8 \\
\hline \multicolumn{4}{|c|}{$\begin{array}{l}\text { Prev. } \\
\text { Chemotherapy }\end{array}$} \\
\hline & $\begin{array}{l}\text { 1, including } \\
\text { platinum }\end{array}$ & 12 & 66.7 \\
\hline & $\begin{array}{l}2 \text {, including } \\
\text { platinum and } \\
\text { taxanes }\end{array}$ & 6 & 33.3 \\
\hline
\end{tabular}

Response to treatment was evaluated in all 18 patients. Gefitinib was administered orally, with median treatment duration of 3 months (range 2-15 months). We observed 2 partial response (PRs; 11.1\%) and 10 stable diseases (SDs; 55.6\%), for an overall disease control rate of $66.7 \%$ (95\% confidence interval $59.2 \%$ to $74.3 \%$ ) 
(Table 2). For the entire population, median TTP was 2.9 months (95\% confidence interval 2.3 to 3.2 months) and median PFS was 3 months (95\% confidence interval 2.4 to 3.6 months) (Figure 1), median OS from start of gefitinib was 8.4 months (95\% confidence interval 5 to 11.8 months) (Figure 2). Univariate analysis of prognostic factor revealed that only duration of gefitinib treatment as a constant factor showed a significant impact on OS. There was no impact on OS from the following factors, PS, gender, smoking, histology and stage, response to primary treatment and response to gefitinib. On the other hand both response to gefitinib and duration of treatment of gefitinib showed a significant impact on PFS, adenocarcinoma subtype and PS 1 showed trend to have an impact on PFS, while other factors including gender, smoking, stage and response to $1^{\text {st }}$ line treatment didn’t show impact on PFS (Table 3).



Figure 1: Progression Free Survival (18 Patients).

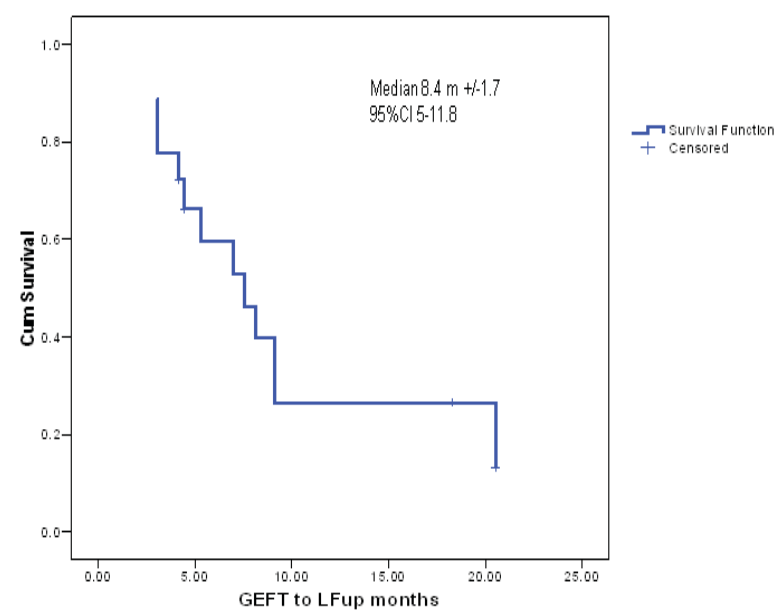

Figure 2: Overall Survival After Start of Gefitinib (18 Patients).

Table 2: Response to Gefitinib (18 Patients).

\begin{tabular}{lcc}
\hline Response & No. & \% \\
\hline CR & 0 & 0 \\
PR & 2 & 11.1 \\
SD & 10 & 55.6 \\
Disease Control Rate & 12 & 66.7 \\
PD & 6 & 33.3 \\
\hline
\end{tabular}

Table 3: Univariete Analysis of Prognostic Factors.

\begin{tabular}{|c|c|c|c|c|c|}
\hline \multirow[t]{2}{*}{ Factor } & & \multicolumn{2}{|c|}{ PFS } & \multicolumn{2}{|c|}{ OS } \\
\hline & & Median & $\mathrm{P}$ & Median & $\mathrm{p}$ \\
\hline \multicolumn{6}{|l|}{ PS } \\
\hline & 1 & 5 & 0.067 & 18.6 & 0.36 \\
\hline & 2 & 2.9 & & 22.5 & \\
\hline \multicolumn{6}{|l|}{ Gender } \\
\hline & Male & 3 & 0.83 & 18.6 & 0.65 \\
\hline & Female & 3 & & 22.5 & \\
\hline \multicolumn{6}{|l|}{ Smoking } \\
\hline & Yes & 3 & 0.34 & 20.1 & 0.54 \\
\hline & No & 3 & & 22.5 & \\
\hline \multicolumn{6}{|l|}{ Histology } \\
\hline & Adenocarcinoma & 4 & 0.079 & 18.6 & 0.23 \\
\hline & Squamous & 3 & & 23.1 & \\
\hline \multicolumn{6}{|l|}{ Stage } \\
\hline & IIIB & 4 & O 41 & 23.1 & 0.32 \\
\hline & IV & 2.9 & 0.41 & 18.6 & \\
\hline $\begin{array}{l}\text { Response } \\
1^{\text {st }} \text { line }\end{array}$ & & & 0.31 & & 0.25 \\
\hline $\begin{array}{l}\text { Response } \\
\text { Gefitinib }\end{array}$ & & & 0.001 & & 0.13 \\
\hline $\begin{array}{l}\text { Duration } \\
\text { Gefitinib }\end{array}$ & & & 0.00001 & & 0.035 \\
\hline
\end{tabular}

All 18 patients were evaluated for toxicity. Side effects were generally mild and considered of grade 2 and 3 skin toxicities, reported in 33.3\% of patients and pruritus in $11.1 \%$ of patients, grade 2 and 3 diarrhea reported in $16.7 \%$ of patients and nausea and vomiting reported in $11.1 \%$ of patients (Table 4). Symptom outcome was observed in all 18 patients and symptomatic improvement and symptom stabilization were observed in $24.7 \%$ and $49 \%$ of patients, respectively.

Table 4: Grade 2 and 3 Toxicities (18 Patients).

\begin{tabular}{lccc}
\hline Toxicity & & No. & $\%$ \\
\hline Skin & & & \\
& Rash & 6 & 33.3 \\
& Pruritus & 2 & 11.1 \\
\hline GIT & Diarrhea & 3 & 16.7 \\
& Anorexia & 1 & 0.6 \\
& Nausea/Vomiting & 2 & 11.1 \\
\hline Metabolic & & & \\
& ALT & 2 & 11.1 \\
& AST & 1 & 0.6 \\
\hline Whole Body & Asthenia & 1 & \\
& & & 0.6 \\
\hline
\end{tabular}

\section{DISCUSSION}

Treatment of patients with advanced non-small cell lung cancer (NSCLC) who have relapsed after an initial chemotherapy regimen for advanced disease is a difficult problem. Small molecule epidermal growth factor receptor (EGFR) inhibitors (gefitinib, erlotinib) were initially developed for use as second-line therapy after failure with a cytotoxic chemotherapy regimen ${ }^{12,16}$. 
This open label pilot study conducted in King Faisal specialist hospital and research center evaluated the efficacy and safety of daily oral dose of $250 \mathrm{mg}$ of gefitinib in patients with locally advanced or metastatic NSCLC who had previously received either one or more chemotherapy regimens (at least one of them contained platinum). This study demonstrated 2 partial response (PRs; 11.1\%) and 10 stable diseases (SDs; 55.6\%), for an overall disease control rate of $66.7 \%$ (95\% confidence interval $59.2 \%$ to $74.3 \%$ ) with no CR reported in our study. These results are similar to those reported in multiple phase II trials; Cappuzzo et al. ${ }^{12}$ reported $15.9 \%$ partial responses and $42.8 \%$ stable disease, for an overall disease control rate of $58.7 \%$. Another phase II trial randomizing 2 doses of gefitinib (250 mg versus 500mg), reported $17.5 \%$ partial responses and $35.9 \%$ stable disease, for an overall disease control rate of $53.4 \%{ }^{16}$. A third phase II trial showed a lower response to gefitinib, of 172 patients evaluable for efficacy, 7 (4.1\%; 95\% CI; 1.7-8.2\%) experienced a partial response (PR); 60 patients (34.9\%) had stable disease (SD) as their best response $\mathrm{e}^{17}$. The results in current trial compared to the previously mentioned phase II trials demonstrated that the current trial had more patients with stable disease.

After a median follow-up of 11.2 months, the median TTP was 2.9 months (95\% confidence interval 2.3 to 3.2 months) and median PFS was 3 months (95\% confidence interval 2.4 to 3.6 months), median OS from start of gefitinib was 8.4 months (95\% confidence interval 5 to 11.8 months). These survival data are higher than that reported in most of the phase II trials; Cappuzzo et al $^{12}$ reported median TTP of 3.3 months and median OS of 4.1 months which is lower than that reported in current trial (8.4 months). Fukuoka et al. ${ }^{16}$ reported survival data equivalent to ours in gefitinib dose of $250 \mathrm{mg}$ with median PFS of 2.7 months and median OS 7.6 months. In the Iressa Survival Evaluation in Lung Cancer (ISEL) trial, 1692 patients were randomly assigned to gefitinib or placebo ${ }^{13}$. All patients had failed prior systemic chemotherapy and were not considered candidates for additional chemotherapy. The trial failed to demonstrate a statistically significant improvement in median survival gefitinib (5.6 versus 5.1 months with placebo), even when the analysis was restricted to patients with adenocarcinoma (6.3 versus 5.4 months). In contrast, planned subset analyses in never-smokers and those of Asian ethnicity showed significantly longer survival compared to placebo (8.9 versus 6.1 months and 9.5 versus 5.5 months, respectively $)^{13,14}$. In the Iressa NSCLC Trial Evaluating Response and Survival versus Taxotere (INTEREST) trial, 1466 patients were randomly assigned to gefitinib or docetaxel, which has been a standard drug use for second-line chemotherapy ${ }^{18}$. Survival in patients treated with gefitinib was not statistically significant different from docetaxel (median 7.6 versus 8.0 months, hazard ratio 1.02, 95\% CI 0.91-1.15). These results fulfilled the predefined conditions for noninferiority. Similar findings were noted in a smaller Japanese trial comparing gefitinib and docetaxe ${ }^{19}$. There were no statistically significant differences in progression-free or overall survival. However, the trial was not designed to demonstrate noninferiority and a clinically significant inferiority to docetaxel could not be excluded ${ }^{20}$. Gefitinib may prolong survival in Asian patients with adenocarcinoma and characteristic EGFR mutations ${ }^{21}$. In a historical comparison of 330 Asian patients with advanced adenocarcinoma before and after the commercial introduction of gefitinib, the median survival was significantly increased in patients with an EGFR mutation once gefitinib was available (27.2 versus 13.6 months prior to its commercialization). In contrast, survival was not significantly increased in those without an EGFR mutation (13.2 versus 10.4 months). Better outcomes in Asian patients were also noted in the ISEL trial ${ }^{14}$. On the other hand erlotinib, which is the second EGFR TKI, showed a survival benefit over best supportive care ${ }^{22}$. In this trial, 731 such patients were randomly assigned to treatment with erlotinib or placebo.The following significant benefits were noted with erlotinib; an increase in the objective response rate (9 versus $<1$ percent with placebo), an increase in overall survival (6.7 versus 4.7 months).

Although the overall objective response rate in previously treated patients given EGFR inhibitors is low, many patients achieve stable disease that can be associated with a survival benefit ${ }^{23}$. Multiple phase II studies ${ }^{17,24-26}$ and a phase III randomized trial ${ }^{22}$ identified a series of clinical parameters associated with clinical responsiveness. These include the following; adenocarcinoma including bronchoalveolar, women, nonsmokers and Asians.

Many of these clinical parameters may be mediated through differences in the frequency of EGFR and k-Ras mutations. As an example, EGFR mutations are more common in those with adenocarcinoma and in Asian populations and k-Ras mutations are less frequent in both of these groups $s^{27,28}$. However, these factors are not absolute. Even for poor prognosis subsets (i.e., men, non-adenocarcinoma histology, non-Asian ethnicity and current or former smokers), there was a reduction in the hazard ratio for death among patients treated with erlotinib. The adverse effect of active cigarette smoking may be mediated in part by increased metabolism of erlotinib thereby decreasing exposure to the $\operatorname{drug}^{29}$. After a single dose of $150 \mathrm{mg}$, the total drug exposure (as reflected by the area under the curve) was 2.8-fold lower in smokers than in nonsmokers at a comparable dose. Although a single dose of $300 \mathrm{mg}$ in smokers yields a plasma concentration similar to that at $150 \mathrm{mg}$ in nonsmokers without an increase in toxicity, additional study is required to determine whether this dose escalation has any therapeutic value ${ }^{30}$.

Clinical correlation studies have found that EGFR protein over expression, gene amplification and specific activating mutations in the TK domain of the EGFR 
(exon 19 deletions, L858R point mutation in exon 21) are associated with increased responsiveness to either gefitinib or erlotinib ${ }^{31,32}$. The impact of EGFR mutations on prognosis may be modified by the presence of nuclear expression of estrogen receptor beta (ER-beta) ${ }^{33}$. Multiple studies have shown that ER-beta is expressed in more than one-half of patients with NSCLC ${ }^{34,35}$. In a Japanese study of 447 patients with resected adenocarcinoma of the lung, ER-beta expression was significantly more frequent in those with an EGFR mutation than in those with EGFR wild-type tumors (70 versus 37 percent). Furthermore, those with an EGFR mutation and strong ER-beta expression had a significantly better prognosis than those with an EGFR mutation but without ER-beta expression. ER-beta expression did not affect prognosis in those without an EGFR mutation.

Whether or not these molecular markers provide more information than clinical parameters is unclear. As an example, in the phase III trial comparing erlotinib to placebo, tissue from 325 of 731 patients was analyzed for over expression of the EGFR protein, gene amplification and mutations in the TK domain of the receptor ${ }^{36}$.

Gefitinib may prolong survival in Asian patients with adenocarcinoma and characteristic EGFR mutations $^{21}$. In a historical comparison of 330 Asian patients with advanced adenocarcinoma before and after the commercial introduction of gefitinib, the median survival was significantly increased in patients with an EGFR mutation once gefitinib was available (27.2 versus 13.6 months prior to its commercialization). In contrast, survival was not significantly increased in those without an EGFR mutation (13.2 versus 10.4 months). Better outcomes in Asian patients were also noted in the ISEL trial $^{14}$.

IPASS trial - in a phase III trial conducted in Asia, 1217 previously untreated patients with advanced NSCLC were randomly assigned to gefitinib or carboplatin plus paclitaxel ${ }^{37}$. Preliminary results were presented at the European Society for Medical Oncology (ESMO) meeting in 2008. Overall, progression-free survival was better with erlotinib compared to chemotherapy (HR 0.74, 95\% CI 0.65-0.85), while overall survival was similar (HR 0.91, 95\% CI 0.76-1.10). The objective response rate was significantly higher with gefitinib (43 versus 32 percent). In preplanned subset analyses, results were compared based upon EGFR mutation status. For patients whose tumors contained an EGFR mutation, PFS was markedly improved with gefitinib (HR 0.48, 95\% CI 0.36-0.64). In contrast, for patients without an EGFR mutation, gefitinib was inferior to chemotherapy (HR 2.85, 95\% CI 2.05-3.98).

Current trial did not show any survival significance in any of these factors and the only factor that showed prognostic influence in OS is duration of gefitinib treatment, may be because of small number of cases.
Gefitinib in current trial was tolerable and there was no major side effects to its use and most of these side effects were grade 2 and 3 and manageable. The most common toxicities were skin rash and diarrhea which is similar to that reported in most of the published trials.

\section{CONCLUSION}

Oral gefitinib at $250 \mathrm{mg} / \mathrm{d}$ provides clinically significant durable antitumor activity, accompanied by clinically meaningful symptom relieves second and third line treatment in patients with advanced NSCLC who have received previous platinum-based therapy.

\section{REFERENCES}

1. Ferlay J, Pisani P. Globocan 2000: Cancer incidence, mortality and prevalence worldwide.2001. Version 1.0. IARC Cancer Base No. 5. IARC Press, Lyon.

2. Schiller JH. Current standards of care in small-cell and non-small-cell lung cancer. Oncology 2001;61 Suppl 1:3-13.

3. Burdett S, Burdett S, Stephens R, Stewart L, Tierney J, Auperin A, et al. Chemotherapy in addition to supportive care improves survival in advanced non-small-cell lung cancer: A systematic review and meta-analysis of individual patient data from 16 randomized controlled trials. J.Clin.Oncol. 2008;26(28):4617-25.

4. Ries L, Kosary C. SEER cancer statistics review, 19731998. Bethesda, MD: National Cancer Institute; 1999.

5. Fossella FV, Lee JS, Hong WK. Management strategies for recurrent non-small cell lung cancer. Semin.Oncol. 1997 Aug;24(4):455-62.

6. Klastersky J, Paesmans M. Response to chemotherapy, quality of life benefits and survival in advanced nonsmall cell lung cancer: Review of literature results. Lung Cancer 2001 Dec;34 Suppl 4:S95-101.

7. Shepherd FA, Dancey J, Ramlau R, Mattson K, Gralla $\mathrm{R}$, O'Rourke M, et al. Prospective randomized trial of docetaxel versus best supportive care in patients with non-small-cell lung cancer previously treated with platinum-based chemotherapy. J.Clin.Oncol. 2000 May;18(10):2095-103.

8. Hanna N, Shepherd FA, Fossella FV, Pereira JR, De Marinis F, von Pawel J, et al. Randomized phase III trial of pemetrexed versus docetaxel in patients with non-small-cell lung cancer previously treated with chemotherapy. J.Clin.Oncol. 2004 May 1;22(9):1589-97.

9. Ciardiello F, Caputo R, Bianco R, Damiano V, Pomatico $\mathrm{G}$, De Placido S, et al. Antitumor effect and potentiation of cytotoxic drugs activity in human cancer cells by ZD-1839 (Iressa), an epidermal growth factor receptorselective tyrosine kinase inhibitor. Clin.Cancer Res. 2000 May;6(5):2053-63.

10. Wakeling AE, Guy SP, Woodburn JR, Ashton SE, Curry BJ, Barker AJ, et al. ZD1839 (Iressa): An orally active inhibitor of epidermal growth factor signaling with potential for cancer therapy. Cancer Res. 2002 Oct 15;62(20):5749-54. 
11. Herbst RS, Maddox AM, Rothenberg ML, Small EJ, Rubin EH, Baselga J, et al. Selective oral epidermal growth factor receptor tyrosine kinase inhibitor ZD1839 is generally well-tolerated and has activity in non-smallcell lung cancer and other solid tumors: Results of a phase I trial. J.Clin.Oncol. 2002 Sep 15;20(18):3815-25.

12. Cappuzzo F, Gregorc V, Rossi E, Cancellieri A, Magrini E, Paties CT, et al. Gefitinib in pretreated Non-SmallCell Lung Cancer (NSCLC): Analysis of efficacy and correlation with HER2 and epidermal growth factor receptor expression in locally advanced or metastatic NSCLC. J.Clin.Oncol. 2003 Jul 15;21(14):2658-63.

13. Hirsch FR, Varella Garcia M, Bunn PA,Jr, Franklin WA, Dziadziuszko R, Thatcher N, et al. Molecular predictors of outcome with gefitinib in a phase III placebocontrolled study in advanced non-small-cell lung cancer. J.Clin.Oncol. 2006 Nov 1;24(31):5034-42.

14. Chang A, Parikh P, Thongprasert S, Tan EH, Perng RP, Ganzon D, et al. Gefitinib (IRESSA) in patients of Asian origin with refractory advanced non-small cell lung cancer: Subset analysis from the ISEL study. J.Thorac. Oncol. 2006;1(8):847-55.

15. Therasse P, Arbuck SG, Eisenhauer EA, Wanders J, Kaplan RS, Rubinstein L, et al. New guidelines to evaluate the response to treatment in solid tumors. European Organization for Research and Treatment of Cancer, National Cancer Institute of the United States, National Cancer Institute of Canada. J.Natl.Cancer Inst. 2000 Feb 2;92(3):205-16.

16. Fukuoka M, Yano S, Giaccone G, Tamura T, Nakagawa K, Douillard JY, et al. Multi-institutional randomized phase II trial of gefitinib for previously treated patients with advanced non-small-cell lung cancer (The IDEAL 1 Trial) (corrected). J.Clin.Oncol. 2003 Jun 15;21(12):2237-46.

17. Janne PA, Gurubhagavatula S, Yeap BY, Lucca J, Ostler P, Skarin AT, et al. Outcomes of patients with advanced non-small cell lung cancer treated with gefitinib (ZD1839, "Iressa") on an expanded access study. Lung Cancer 2004 May;44(2):221-30.

18. Kim ES, Hirsh V, Mok T, Socinski MA, Gervais R, Wu YL, et al. Gefitinib versus docetaxel in previously treated non-small-cell lung cancer (INTEREST): A randomised phase III trial. Lancet 2008;372(9652):1809-18.

19. Maruyama R, Nishiwaki Y, Tamura T, Yamamoto N, Tsuboi M, Nakagawa K, et al. Phase III study, V-1532, of gefitinib versus docetaxel in previously treated Japanese patients with non-small-cell lung cancer. J.Clin. Oncol. 2008;26(26):4244-52.

20. Dahlberg SE, Gray RJ, Johnson BE. Gefitinib for recurrent non-small-cell lung cancer: All things are not created equal. J.Clin.Oncol. 2008;26(26):4233-5.

21. Takano T, Fukui T, Ohe Y, Tsuta K, Yamamoto S, Nokihara $\mathrm{H}$, et al. EGFR mutations predict survival benefit from gefitinib in patients with advanced lung adenocarcinoma: A historical comparison of patients treated before and after gefitinib approval in Japan. J.Clin.Oncol. 2008;26(34):5589-95.
22. Shepherd FA, Rodrigues Pereira J, Ciuleanu T, Tan EH, Hirsh V, Thongprasert S, et al. Erlotinib in previously treated non-small-cell lung cancer. N.Engl.J.Med. 2005 Jul 14;353(2):123-32.

23. Kurata T, Matsuo K, Takada M, Kawahara M, Tsuji $\mathrm{M}$, Matsubara $\mathrm{Y}$, et al. Is the importance of achieving stable disease different between epidermal growth factor receptor tyrosine kinase inhibitors and cytotoxic agents in the second-line setting for advanced non-small cell lung cancer? J.Thorac.Oncol. 2006;1(7):684-91.

24. Pérez Soler R, Chachoua A, Hammond LA, Rowinsky EK, Huberman M, Karp D, et al. Determinants of tumor response and survival with erlotinib in patients with non-small-cell lung cancer. J.Clin.Oncol. 2004;22(16): 3238-47.

25. Gandara DR, West H, Chansky K, Davies AM, Lau $\mathrm{DH}$, Crowley J, et al. Bronchioloalveolar carcinoma: A model for investigating the biology of epidermal growth factor receptor inhibition. Clin.Cancer Res. 2004 Jun 15;10(12 Pt 2):4205s-9s.

26. Miller VA, Kris MG, Shah N, Patel J, Azzoli C, Gomez $\mathrm{J}$, et al. Bronchioloalveolar pathologic subtype and smoking history predict sensitivity to gefitinib in advanced non-small-cell lung cancer. J.Clin.Oncol. 2004 Mar 15;22(6):1103-9.

27. Wu CC, Hsu HY, Liu HP, Chang JW, Chen YT, Hsieh WY, et al. Reversed mutation rates of KRAS and EGFR genes in adenocarcinoma of the lung in Taiwan and their implications. Cancer 2008;113(11):3199-208.

28. Marks JL, Broderick S, Zhou Q, Chitale D, Li AR, Zakowski MF, et al. Prognostic and therapeutic implications of EGFR and KRAS mutations in resected lung adenocarcinoma. J.Thorac.Oncol. 2008;3(2):111-6.

29. Hamilton M, Wolf JL, Rusk J, Beard SE, Clark GM, Witt K, et al. Effects of smoking on the pharmacokinetics of erlotinib. Clin.Cancer Res. 2006 Apr 1;12(7 Pt 1) :2166-71.

30. Hughes AN, O'Brien MER, Petty WJ, Chick JB, Rankin E, Wall PJ, et al. Overcoming CYP1A1/1A2 mediated induction of metabolism by escalating erlotinib dose in current smokers. J.Clin.Oncol. 2009;27(8):1220-6.

31. Tokumo M, Toyooka S, Kiura K, Shigematsu H, Tomii $\mathrm{K}$, Aoe $\mathrm{M}$, et al. The relationship between epidermal growth factor receptor mutations and clinicopathologic features in non-small cell lung cancers. Clin.Cancer Res. 2005 Feb 1;11(3):1167-73.

32. Yang CH, Yu CJ, Shih JY, Chang YC, Hu FC, Tsai MC, et al. Specific EGFR mutations predict treatment outcome of stage IIIB/IV patients with chemotherapy-naive non-small-cell lung cancer receiving first-line gefitinib monotherapy. J.Clin.Oncol. 2008;26(16):2745-53.

33. Nose N, Sugio K, Oyama T, Nozoe T, Uramoto H, Iwata T, et al. Association between estrogen receptor-â expression and epidermal growth factor receptor mutation in the postoperative prognosis of Adenocarcinoma of the lung. J.Clin.Oncol. 2009;27(3):411-7.

34. Schwartz AG, Prysak GM, Murphy V, Lonardo F, Pass H, Schwartz J, et al. Nuclear estrogen receptor beta in lung 
cancer: Expression and survival differences by sex. Clin. Cancer Res. 2005 Oct 15;11(20):7280-7.

35. Skov BG, Fischer BM, Pappot H. Oestrogen receptor â over expression in males with non-small cell lung cancer is associated with better survival. Lung Cancer 2008;59(1):88-94.

36. Tsao MS, Sakurada A, Cutz JC, Zhu CQ, Kamel Reid $\mathrm{S}$, Squire J, et al. Erlotinib in lung cancer - molecular and clinical predictors of outcome. N.Engl.J.Med. 2005 Jul 14;353(2):133-44.

37. Giaccone G, Gallegos Ruiz M, Le Chevalier T, Thatcher $\mathrm{N}$, Smit E, Rodriguez JA, et al. Erlotinib for frontline treatment of advanced non-small cell lung cancer: A phase II study. Clin.Cancer Res. 2006 Oct 15;12 (20 Pt 1) :6049-55. 